Research Article

\title{
Association of bone age with overweight and obesity in children in the age group of 8 to 11 years
}

\section{Godfrey D. A., Umapathy P.*, Latha Ravichandran, Elayaraja S., Shilpa Senthil Murugan, Srinivasan V.}

Department of Paediatrics, Sri Ramachandra University, Chennai, India

Received: 16 April 2016

Revised: 30 May 2016

Accepted: 08 June 2016

\section{*Correspondence:}

Dr. Umapathy P.,

E-mail: drumapathy07@gmail.com

Copyright: ( $)$ the author(s), publisher and licensee Medip Academy. This is an open-access article distributed under the terms of the Creative Commons Attribution Non-Commercial License, which permits unrestricted non-commercial use, distribution, and reproduction in any medium, provided the original work is properly cited.

\section{ABSTRACT}

Background: Obesity is one of the most common nutritional problems in developed countries. The prevalence of obesity is rapidly progressing in children. It is associated with serious health hazards in adolescence and especially in adulthood, like hypertension, coronary artery disease, diabetes mellitus, etc.

Methods: A cross sectional study was conducted on 60 children fulfilling the inclusion criteria aged 8 to 11 years, of which 30 children were obese and 30 children were overweight. The body mass index (BMI) values of the children were plotted against the corresponding WHO charts. Children were segregated as overweight and Obese based on the BMI. Based on a radiological examination of skeletal development of the left-hand wrist, bone age is assessed and then compared with the chronological age.

Results: Among the study population the mean bone age index of obese children was 1.08615 and the mean bone age index of overweight children was 0.98097 which was statistically significant. Bone age index $=0.016(\mathrm{BMI})+0.6742$. By using this formula we derived that a BMI of 19 or above triggered significant acceleration of bone age.

Conclusions: In our study by deriving at the bone age index of both obese and overweight children and comparing them, we found that the trends of obesity affecting the bone age is significantly more than overweight children. Hence the lifestyle modifications in overweight children are vital so as not to get into obese category. This will prevent the bone age changes which in turn will avoid serious health hazards in adolescence and especially in adulthood.

Keywords: Obesity and bone age, Paediatric obesity, Early bone age advancement, Overweight and obesity

\section{INTRODUCTION}

Overweight is defined as having excess body weight for a particular height from fat, muscle, bone, water, or a combination of these factors. Obesity is defined as having excess body fat. ${ }^{1,2}$ The prevalence of obesity is rapidly progressing in children. It is associated with serious health hazards in adolescence and especially in adulthood. The risk of overweight children becoming obese is alarming. The skeletal maturation process involves transformation of the cartilaginous epiphyseal growth plate into bone, which proceeds as a child grows and matures. Once the epiphyseal plate ossifies an individual reaches final adult height. Influence of hormones and other factors play an important role in progression of skeletal maturation. Obese children during prepubertal years have higher height velocity and accelerated bone age compared to lean subjects. However, this prepubertal advantage in growth tends to gradually decrease during puberty, obese children show a reduced growth spurt compared with lean subjects thereby decreasing the final height of obese children. The fact that obese children have advanced bone age tells us that BMI is directly proportional to accelerated bone age. 
Therefore it is imperative to analyses if there was a significant variation in the association of bone age in obese and overweight children. Hence this study is aimed at deriving a formula by which the BMI which triggers the bone changes can be identified.

\section{METHODS}

A cross sectional study was conducted on children fulfilling the inclusion criteria aged 8 to 11 years from the outpatient and the inpatient of Sri Ramachandra Medical College in Paediatrics department. A detailed proforma including the date of birth of the child, child's anthropometric details and other associated lifestyle questioners were filled by the investigator. The birth certificate was verified of the child for appropriate age. After getting an informed consent from the children the height was measured using a stapidometer, child's heels are kept slightly apart such that weight is borne equally on both legs, posterior prominences are made to touch the back, frankfurt plane-the line joining the floor of the external auditory meatus to the lower border of the orbit and the biauricular line are horizontal, the movable head piece is kept firmly over the vertex and height is measured. The weight was measured by using a weighing machine where the child is made to step on the scale platform, facing away from the scale read out, with both feet on the platform, and remain still with arms hanging naturally at side and looking forward and the weight in kilograms was taken. Their BMI was calculated using the formulae $\mathrm{BMI}=$ weight in $\mathrm{kg} /$ height in meter $\mathrm{x}$ height in meter. The BMI values were then plotted against the corresponding WHO charts (i.e.) in accordance to the age and sex was plotted. Children whose BMI was between $85^{\text {th }}$ to $97^{\text {th }}$ percentile was marked as overweight. Children whose BMI was more than $97^{\text {th }}$ percentile was marked as obese. By using the above procedure 30 overweight children and 30 obese children were chosen.

The BMI number is plotted on the WHO BMI for age growth charts (for either girls or boys) to obtain a percentile ranking. Percentiles are the most commonly used indicator to assess the size and growth patterns of individual children among children of the same sex and age. Growth chart consists of an $\mathrm{x}$ axis which is usually age in years or months and a $y$ axis that changes according to the reference e.g., it can be height in $\mathrm{cm}$ or inches, weight in $\mathrm{kg}$ or body mass index in $\mathrm{kg} / \mathrm{m}^{2}$.The $X$ axis is usually divided into 12 equal parts (months) for each year. Standard growth chart has 7 percentile lines and include $3^{\text {rd }}, 10^{\text {th }}, 25^{\text {th }}, 50^{\text {th }}, 75^{\text {th }}$ and $97^{\text {th }}$ percentiles. These percentiles are standard for height and weight charts. Any individual who is below $3^{\text {rd }}$ and above $97^{\text {th }}$ percentile is considered out of normal range. For the BMI charts, however, there are $85^{\text {th }}$ and $97^{\text {th }}$ percentile lines which indicate overweight and obesity cut offs. The percentile indicates the relative position of the child's BMI number. The weight status categories used with children and teens (underweight, healthy weight, overweight, and obese). The amount of body fat differs between girls and boys and with age. The BMI for age growth charts for girls and boys take into account these differences and allow translation of a BMI number into a percentile for a child's or teen's sex and age.

BMI is used as a screening tool to identify possible weight problems for children. CDC and the American academy of paediatrics (AAP) recommend the use of BMI to screen for overweight and obesity in children beginning at 2 years old.

\section{Bone age assessment}

Bone age assessment is a procedure frequently performed in paediatric radiology. Based on a radiological examination of skeletal development of the left-hand wrist, bone age is assessed and then compared with the chronological age. A discrepancy between these two values indicates abnormalities in skeletal development. The procedure is often used in the management and diagnosis of endocrine disorders and it can also serve as an indication of the therapeutic effect of treatment. ${ }^{13}$ Generally, it can indicate whether the growth of a patient is accelerating or decreasing. In many cases the decision whether to treat a patient with growth hormones depends on the outcome of this test. This examination is universally used due to its simplicity, minimal radiation exposure, and the availability of multiple ossification centres for evaluation of maturity. The main clinical methods for skeletal bone age evaluation are the Greulich and Pyle (GP) method and the Tanner e Whitehouse (TW2) method. ${ }^{14,15}$ There are several differences between the two methods. The $\mathrm{G}$ and $\mathrm{P}$ method is most widely used in the Netherlands. This is mainly because the $G$ and $P$ method is faster and easier to use than the TW2 method. However, research has shown that the two methods produce different values for skeletal age and that these differences are significant in clinical practice. According to Bull the TW2 method is the more reproducible of the two and also potentially more accurate. ${ }^{16}$ Although he states that it has never actually been shown to be more accurate.

After counselling the parents an X-ray involving both the elbow and wrist were taken for the children. These $\mathrm{X}$ rays were then interpreted by a radiologist who interpreted the bone age of the chid in months. We decided on taking both the elbow and the wrist X-ray because our primary interpretation of children in our study aged 8 to 11 years was based on the ossification of pisiform 8-12 years, olecranon-9 years and the external epicondyle-11 years along with other features in the tanners white house method. Once the bone age resulted by the radiologist, the bone age index was calculated by using the formulae:

Bone age index $=$ bone age/chronological age.

Once the bone age index was calculated, the association of bone age index in overweight and obese children were 
arrived at using the chi-square test. Also a correlation graph was established. By using the coefficient regression formulae over the graph, a formula for bone age index for overweight and obese children in the age group of 8 to 11 years was arrived at.

Coefficient regression equation: $\mathrm{Y}=\mathrm{a}+\mathrm{bx}$

- $\quad \mathrm{b}$ is the gradient; slope or regression coefficient

- $\mathrm{a}$ is the intercept of the line at $\mathrm{Y}$ axis or regression constant

- $\quad \mathrm{Y}$ is a value for the outcome (bone age index)

- $\mathrm{X}$ is a value for the predictor (body mass index)

\section{Inclusion criteria}

Children between the age group of 8 to 11 , who are either overweight or obese as per WHO criteria.

\section{Exclusion criteria}

Children who are documented cases of skeletal dysplasia, hypothyroidism, CAH, systemic illness, muscular dystrophies, rickets, precocious puberty and hormonal therapy.

\section{RESULTS}

A total of 60 children were involved in our study, of which 30 children were obese and 30 children were overweight from the age group of 8 to 11 years. Among the 60 children included in the study most of the children were from the age group of 10 to 11 years (48.3\%). Most of the children from the obese group were from the age group of 8 to 9 years and most of the obese category were female $(66.7 \%)$. Most children in the overweight children were from the age group of 10 to 11 years and were male. Overall $55 \%$ of children involved in the study were female. Most of the obese children were from the BMI percentile of $>99^{\text {th }}$ percentile.

The mean weight of obese children was 40.97 and over weight were 34.17 which were statistically significant. The mean bone age of obese children was 119.67 months and overweight children were 111.2 months which was statistically significant. In healthy weighted subjects bone age was delayed by 6.63 months, negligibly advanced for overweight and 18.10 months advanced for obese subjects. $^{20}$

Table 1: Age distribution (in Nos and \% terms).

\begin{tabular}{|c|c|c|c|c|c|c|c|c|c|c|c|c|c|c|}
\hline \multirow{3}{*}{ Age (years) } & \multicolumn{6}{|c|}{ Male } & \multicolumn{6}{|c|}{ Female } & \multirow{2}{*}{\multicolumn{2}{|c|}{ Grand total }} \\
\hline & \multicolumn{2}{|c|}{ Obese } & \multicolumn{2}{|c|}{ Overweight } & \multicolumn{2}{|l|}{ Total } & \multicolumn{2}{|c|}{ Obese } & \multicolumn{2}{|c|}{ Overweight } & \multicolumn{2}{|c|}{ Total } & & \\
\hline & Nos & $\%$ & Nos & $\%$ & Nos & $\%$ & Nos & $\%$ & Nos & $\%$ & Nos & $\%$ & Nos & $\%$ \\
\hline $8-9$ & 5.0 & 18.5 & 4 & 14.8 & 9 & 33.3 & 10 & 30.3 & 7 & 21.2 & 17 & 51.5 & 26 & 43.3 \\
\hline $9-10$ & 0 & 0 & 0 & 0 & 0 & 0 & 4 & 12.1 & 1 & 3 & 5 & 15.1 & 5 & 8.3 \\
\hline $10-11$ & 5 & 18.5 & 13 & 48.2 & 18 & 66.7 & 6 & 18.2 & 5 & 15.2 & 11 & 33.4 & 29 & 48.4 \\
\hline Total & 10 & 37 & 17 & 63 & 27 & 100 & 20 & 60.6 & 13 & 39.4 & 33 & 100 & 60 & 100 \\
\hline
\end{tabular}

Table 2: Sex distribution (in Nos and \% terms).

\begin{tabular}{|lllllllllllllll|}
\hline & \multicolumn{1}{l}{ Obese } & \multicolumn{1}{l}{ Age (years) } & Male & \multicolumn{1}{l}{ Female } & Total & \multicolumn{3}{c}{ Mverweight } \\
& Nos & $\%$ & Nos & $\%$ & Nos & $\%$ & Nos & $\%$ & Nos & $\%$ & Nos & $\%$ & Nos & $\%$ \\
\hline $8-9$ & 5 & 16.7 & 10 & 33.3 & 15 & 50 & 4 & 13.3 & 7 & 23.3 & 11 & 36.7 & 26 & 43.3 \\
\hline $9-10$ & 0 & 0 & 4 & 13.3 & 4 & 13.3 & 0 & 0 & 1 & 3.3 & 1 & 3.3 & 5 & 8.3 \\
\hline $10-11$ & 5 & 16.7 & 6 & 20 & 11 & 36.7 & 13 & 43.3 & 5 & 16.7 & 18 & 60 & 29 & 48.4 \\
\hline Total & 10 & 33.3 & 20 & 66.7 & 30 & 100 & 17 & 56.7 & 13 & 43.3 & 30 & 100 & 60 & 100 \\
\hline
\end{tabular}

The mean bone age index of obese children was 1.08615 and the mean bone age index of overweight children was 0.98097 which was statistically significant. The bone age index was accelerated in obese children. Correlation graphs showed significant acceleration in the bone age index in the obese children when compared to overweight children.
The data for the results from the population under study is arranged and presented in Table 1 and Table 2 revealing the following;

- $\quad$ Obese Children distribution (in Nos and \% terms)

- Overweight Children distribution (in Nos and \% terms) 


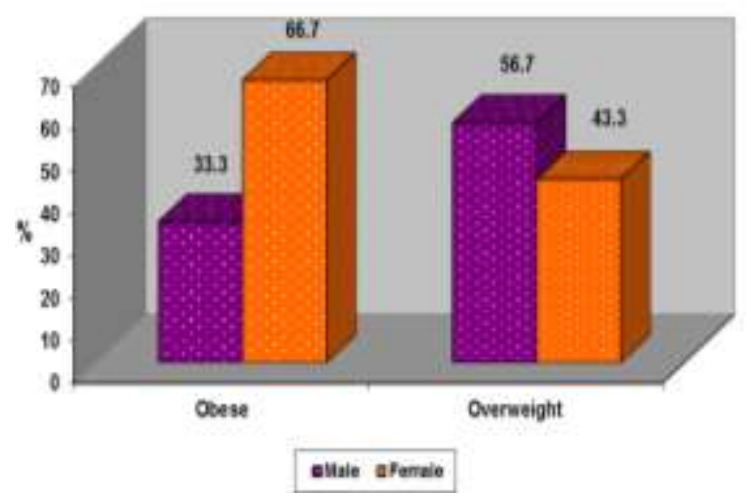

Figure 1: Comparison between sex and group.

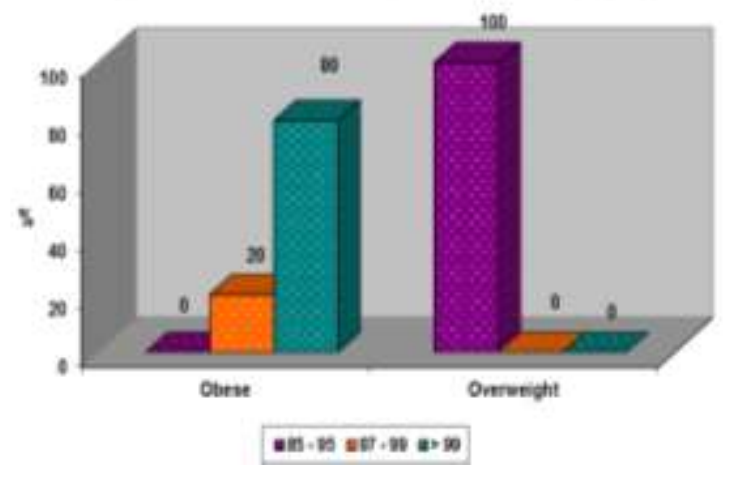

Figure 2: Comparison between BMI percentile and group.

Table 3: Distribution of BMI percentile.

\begin{tabular}{|ll|lll|}
\hline BMI Percentile & Obese & Overweight & Percentage $\%$ & Total \\
\hline $85^{\text {th }}$ to $97^{\text {th }}$ percentile & 0 & 30 & $50 \%$ & 30 \\
\hline $97^{\text {th }}$ to $99^{\text {th }}$ percentile & 6 & 0 & $10 \%$ & 6 \\
\hline$>99^{\text {th }}$ percentile & 24 & 0 & $40 \%$ & 24 \\
\hline Total & 30 & 30 & $100 \%$ & 60 \\
\hline
\end{tabular}

Table 4: Distribution of mean bone age with anthropometry.

\begin{tabular}{|lllll|}
\hline & Height & Weight & $\begin{array}{l}\text { Chronological } \\
\text { age }\end{array}$ & $\begin{array}{l}\text { Mean } \\
\text { bone } \\
\text { age }\end{array}$ \\
\hline Obese & 132.05 & 40.97 & 110.6 & 119.67 \\
\hline Overweight & 132.47 & 34.17 & 113.23 & 111.20 \\
\hline P value & 0.796 & 0.00 & 0.425 & 0.016 \\
\hline
\end{tabular}

Table 5: Mean bone age index.

\begin{tabular}{|llll|}
\hline Age & $\begin{array}{l}\text { Obese } \\
\text { (Mean bone } \\
\text { age index) }\end{array}$ & $\begin{array}{l}\text { Overweight } \\
\text { (mean bone } \\
\text { age index }\end{array}$ & P-value \\
\hline 8-9 years & 1.09465 & 0.97560 & 0.000 \\
\hline 9-10 years & 1.09985 & 1.04340 & 0.117 \\
\hline 10-11years & 1.06957 & 0.98078 & 0.000 \\
\hline Mean & 1.08615 & 0.98097 & 0.000 \\
\hline
\end{tabular}

The distribution of the BMI percentile of the study population is presented in Table 3. Most of the obese children were from the BMI percentile of $>99^{\text {th }}$ percentile. This is clearly shown in Figure 2. The details of height, weight, chronological age and mean bone age w.r.to different groups are given in Table 4.

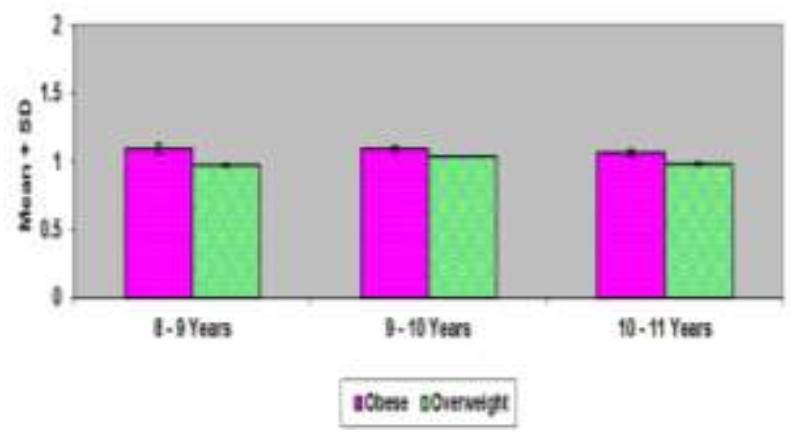

Figure 3: Bone age index in different age groups.

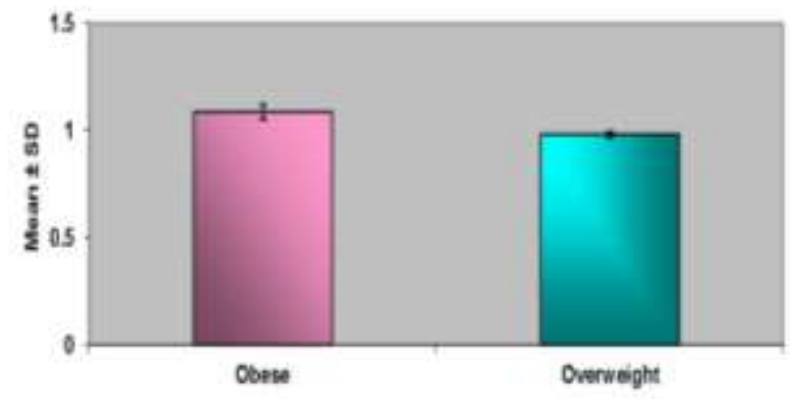

Figure 4: Mean bone age index in obese and overweight children. 
The mean weight of obese children was 40.97 and over weight were 34.17 which were statistically significant. The bone age was accelerated significantly in the obese children. It was not accelerated in the overweight children. This was statistically significant. The mean bone age index of the different groups and different ages are provided in Table 5. The mean bone age index of obese children was 1.08615 and the mean bone age index of overweight children was 0.98097 which was statistically significant as given in Figure 3 and 4.

Correlation graph in obese children between BMI and bone age index is shown in Figure 5.

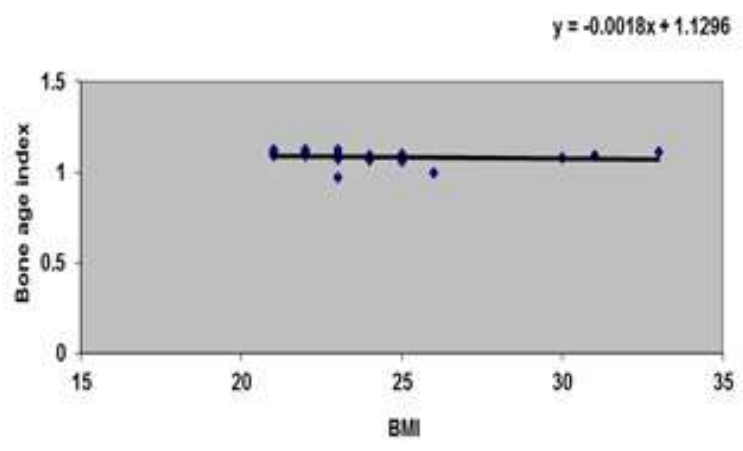

Figure 5: Correlation between BMI and bone age index in obese.

The correlation graph showed significant acceleration in the bone age index in the obese children.

$y=0.0015 x+0.9514$

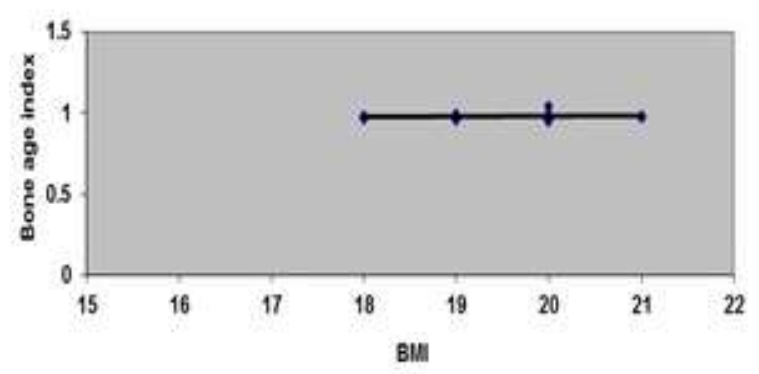

Figure 6: Correlation graph in overweight children between BMI and bone age index.

The correlation graph in the overweight children was not accelarated when compared to the obese children.

The combined correlation graph between BMI and bone age index in Figure 7 shows acceleration of bone age with the BMI. It is significantly more accelerated in the obese children.

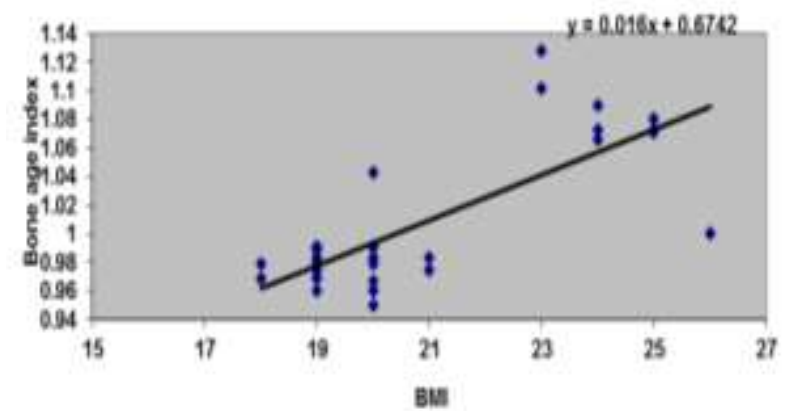

Figure 7: Overall correlation graph.

\section{DISCUSSION}

The body mass index is an important measure to assess the weight of a child. Overweight is defined as having excess body weight for a particular height from fat, muscle, bone, water, or a combination of these factors. ${ }^{1}$ Obesity is defined as having excess body fat. ${ }^{2}$ Obesity is a major global burden and is one of the most common nutritional problems in developed countries. ${ }^{3}$ The prevalence of obesity is rapidly progressing in children. ${ }^{4,5}$ It is associated with serious health hazards in adolescence and especially in adulthood, like hypertension, coronary artery disease, diabetes mellitus, dyslipidemia, cholecystitis, pancreatitis, sleep apnea, and osteoarthritis. The calculated global prevalence of overweight children aged 5-17 years estimated by the International Overweight Task Force (IOTF) to be approximately $10 \% .^{6}$ In the last two decades, the prevalence of obesity has doubled in children and tripled in adolescents in the United States of America, the increase in childhood and adolescent obesity has resulted in an increase in obesity or overweight in adults. This has a profound public health consequence as $80 \%$ of overweight children become overweight adults. The risk of overweight children becoming obese is alarming. ${ }^{7}$ The skeletal maturation process involves transformation of the cartilaginous epiphyseal growth plate into bone, which proceeds as a child grows and matures. Once the epiphyseal plate ossifies an individual reaches final adult height. This complex cascade of events includes parathyroid hormone related peptide (PTHrP), Indian hedgehog, matrix metallo proteinases and vascular endothelial growth factor (VEGF), which are involved in coordinating cellular growth, cellular differentiation, apoptosis, extracellular matrix remodelling and angiogenesis. ${ }^{8}$ Estrogens, androgens and the growth hormone/insulin-like growth factor-1 (GH/IGF-1) axis influence the activity of these factors and the progression of skeletal maturation. ${ }^{9}$ One of the adverse effects of obesity in children is advancement of bone age. ${ }^{10,11}$ Obese children during prepubertal years have higher height velocity and accelerated bone age compared to lean subjects. However, this prepubertal advantage in growth tends to gradually decrease during puberty, obese children show a reduced growth spurt compared with lean subjects 
thereby decreasing the final height of obese children. ${ }^{12}$ Growth hormone $(\mathrm{GH})$ secretion in obese children is reduced, therefore suggesting that increased growth is $\mathrm{GH}$ independent. Factors which have been implicated in the accelerated growth in obese children include increased leptin and insulin levels, adrenal androgens, insulin-like growth factor (IGF)-1, IGF-binding protein-1 and $\mathrm{GH}$-binding proteins. The fact that obese children have advance bone age tells us that BMI is directly proportional to accelerated bone age. Therefore it is imperative to analyse if there was a significant variation in the association of bone age in obese and overweight children. Hence this study will derive a formula by which the BMI which triggers the bone changes can be identified.

Paediatric obesity is a growing epidemic in many countries throughout the world. ${ }^{17}$ As childhood obesity is growing at alarming rates the risk of the metabolic issues prevalent within the obese paediatric patient population is also increasing. Obesity causes various effects in the body which includes orthopaedic changes. Studies done in the past have described the relationship between bone metabolism and obesity. ${ }^{18}$ These orthopaedic complications resulting from obesity cannot be ignored.

One such complication is the advancement of bone age in such children. Though these children appear tall for their age their final height is affected due to the early fusion of the ossification centres. Bone age was accelerated in obese children who also indicate that the increase in bone age is proportional to increasing body mass index. The specific age trigger for bone age acceleration is poorly explained previously. We wanted to explore the trends of bone age in overweight and obese children. We wanted to derive a formula to know the bone age index which triggers the bone age using the correlation graphs.

Among the 60 children included in the study most of the children were from the age group of 10 to 11 years $(48.3 \%)$. Chaumoitre et al who did a study of the influence of BMI and socio economic status on bone age between 6 to 18years had most children between the age group of 15 years. ${ }^{19}$

Most of the children from the obese group were from the age group of 8 to 9 years and most of the obese children were female $(66.7 \%)$. Most children in the overweight children were from the age group of 8 to 9 years and were male. Overall $55 \%$ of children involved in the study were female. Most of the obese children were from the BMI percentile of $>99^{\text {th }}$ percentile.

The mean weight of obese children was 40.97 and over weight were 34.17 which were statistically significant. The mean bone age of obese children was 119.67 months and overweight children were 111.2 months which was statistically significant. Pinero et al stated that in his study there was significant variation of the average calculated bone age. ${ }^{20}$ In healthy weighted subjects bone age was delayed by 6.63 months, negligibly advanced for overweight and 18.10 months advanced for obese subjects. $^{20}$

The mean bone age index of obese children was 1.08615 and the mean bone age index of overweight children was 0.98097 which was statistically significant. This was found to be less than the study done by Sopher et al where it was found that when all subjects were divided by obesity status, obese subjects were more likely to be in the highest $\mathrm{BA} / \mathrm{CA}$ centile which is between 1.170 to 1.303 than non-obese subjects. ${ }^{21}$

The bone age index and the BMI were compared by using the correlation graph where the $\mathrm{Y}$ axis represented the Bone age index and the $\mathrm{X}$ axis represented the BMI. It was noted that there was acceleration of bone age index as the BMI progressed. We aimed at determining the trigger BMI when bone age index increased more than one or which lead to advanced bone age in our study. Our goal was to arrive at a formula for bone age index in obese and overweight children and thereby enable us to know the particular BMI which resulted in bone age advancement. We used the correlation regression formula to attain it which is

\section{Bone age index $=0.016(\mathrm{BMI})+0.6742$}

By using this formula we derived that a BMI of 19 or above triggered significant acceleration of bone age in our study.

\section{CONCLUSION}

The advancement in bone age is a known complication of obesity. This advancement in bone age leads to decrease in the final height of the child. In our study by deriving at the bone age index of both obese and overweight children and comparing them, we found that the trends of obesity affecting the bone age is significantly more than overweight children. The lifestyle modifications in overweight children are vital as this may prevent the bone age changes. By using the trends of the influence of the bone age index and the BMI of obese and overweight children in 8 to 11 years on a correlation graph we derived at formula for bone age index which is as follows:

\section{Bone Age index $=0.016(\mathrm{BMI})+0.6742$}

By using the above formula we found that a BMI of 19 or above was the trigger BMI which caused significant bone age in the children in our study.

\section{Funding: No funding sources Conflict of interest: None declared}

Ethical approval: The study was approved by the Institutional Ethics Committee 


\section{REFERENCES}

1. Ogden CL, Carroll MD, Kit BK, Flegal KM. Prevalence of childhood and adult obesity in the United States, 2011-2012. J Am Med Asso. 2014;311(8):806-14.

2. National center for health statistics. health, united states, 2011: with special features on socioeconomic status and health. Hyattsville, MD; U.S. Department of Health and Human Services;2012.

3. Ells, Campbell K, Lindstone J, Kelly S, Lang R, Summerbell C. Prevention of childhood obesity. Best Pract Res Clin Endocrinol Metab. 2005;19:441-54.

4. Baskin ML, Ard J, Franklin F, Allison DB. Prevalence of obesity in the United States. Obes Rev. 2005;6:5-7.

5. Dehghan M, Akhtar DN, Merchant AT. Childhood obesity, prevalence and prevention. Nutr J. 2005;4:24.

6. Bhave S, Bavdekar A, Otiv M. IAP national task force for childhood prevention of adult diseases: childhood obesity. Indian Pediatr. 2004;41:559-75.

7. Dietz WH. Overweight in childhood and adolescence. N Engl J Med. 2004;350:855-7.

8. Haeusler G, Wakter I, Helmreich M, Egerbacher M. Location of matrix metalloproteinases (MMPs), their tissue inhibitors, and vascular endothelial growth factor (VEGF) in growth plates of children and adolescents indicates a role for MMPs in human postnatal growth and skeletal maturation. Cacif Tissue Int. 2005;76:326-35.

9. Grumbach MM. Estrogen, bone, growth and sex: a sea change in conventional wisdom. J Pediatr Endocrinol Metab. 2000;13(6):1439-55.

10. Klein KO, Lamore KA, Delancey E, Brown JM, Considine RV, Hassink SG. Effect of obesity on estradiol level, and its relationship to leptin, bone maturation, and bone mineral density in children. J Clin Endocrinol Metab. 1998;83:3469-74.

11. Russell DL, Keil MF, Bonat SH, Uwaifo GI, Nicholson JC, Mcduffie JR, et al. The relation between skeletal maturation and adiposity in African American and Caucasian children. J Pediatr. 2001;139:844-8.

12. He Q, Karlberg J: BMI in childhood and its association with height gain, timing of puberty, and final height. Pediatr Res. 2001;49:244-51.

13. Sopher AB1, Jean AM, Zwany SK, Winston DM, Pomeranz CB, Bell JJ, et al. Bone age advancement in prepubertal children with obesity and premature adrenarche: possible potentiating factors. Obesity (silver spring). 2011;19(6):1259-64.

14. Dorst JP. Radiography of infants and children. Am J Dis Child. 1964;107(1):107-8.

15. Greulich WW, Pyle SI: Radiographic atlas of skeletal development of hand wrist, 2nd ed. Stanford, CA: Standford Univ Press, 1971.

16. Murray RO. Assessment of skeletal maturity and prediction of adult height (TW2 Method). Proc R Soc Med. 1976;69(7):542.

17. Ogden CL, Flegal KM, Carroll MD, Johnson CL. Prevalence and trends in overweight among US children and adolescents, 1999-2000. J Am Med Asso. 2002;288:1728-32.

18. Petrou V, Tertipi A, Georgoulas T, Papastathi E, Deligeorgi M, Skarpa V, et al. Childhood obesity and bone age. Endocrine Abstracts. 2009;20:528.

19. Chaumoitre K, Lamtali S, Baali A, Saliba-Serre B, Lahmam A, Aboussad A, et al. Influence of socioeconomic status and body mass index on bone age. Horm Res Paediatr. 2010;74:129-35.

20. Pinero J, Rabinovich RR, Alaia MJ, Feldman DS, Otsuka NY. Does body mass influence skeletal age: an analysis using the tanner-whitehouse 3 method. J Orthopaedics. 2012;9(2):2.

21. Sopher AB, Jean AM, Zwany SK. Bone age advancement in prepubertal children with obesity and premature adrenarche: possible potentiating factors. Obesity. 2011;19(6):1259-64.

Cite this article as: Godfrey DA, Umapathy P, Ravichandran L, Elayaraja S, Murugan SS, Srinivasan V. Association of bone age with overweight and obesity in children in the age group of 8 to 11 years. Int J Contemp Pediatr 2016;3:788-94. 